\title{
ENFERMEIROS DE REABILITAÇÃO E AS ATITUDES FACE À MORTE EM CONTEXTO DE CRISE PANDÉMICA POR COVID-19
}

\author{
ENFERMERAS DE REHABILITACIÓN Y ACTITUDES HACIA LA MUERTE EN EL CONTEXTO \\ DE UNA CRISIS PANDÉMICA POR COVID-19
}

REHABILITATION NURSES AND ATTITUDES TOWARDS DEATH IN THE CONTEXT OF A PANDEMIC CRISIS BY COVID-19

DOI 10.33194/rper.2020.v3.s2.6.5792 | Submetido 06/06/2020 | Aprovado 16/11/2020

\begin{abstract}
Maria Filomena Passos Teixeira Cardoso, 2,3 ${ }^{\mathbb{D}}$; Maria Manuela Ferreira Pereira Da Silva Martins ${ }^{4,5} \mathbb{D}$; Olga Maria Pimenta Lopes Ribeiro ${ }^{4,5}$; Esmeralda Faria Fonseca ${ }^{2}$ (D) Virgínia Lucinda Sousa Cruz Pereira ${ }^{2}$ (D)

1 - Universidade do Porto, Instituto de Ciências Biomédicas Abel Salazar;

2 - Centro Hospitalar Universitário São João; 3 - Universidade Fernando Pessoa; 4 - Escola Superior de Enfermagem do Porto;

5 - Centro de Investigação em Tecnologias e Serviços de Saúde (CINTESIS)
\end{abstract}

\section{RESUMO}

Objetivo: analisar as diferenças no perfil de atitudes dos enfermeiros de reabilitação face à morte antes e depois do primeiro período crítico da pandemia por COVID-19.

Método: estudo quantitativo, comparativo, antes e depois do período crítico. A colheita de dados ocorreu através de questionário de autopreenchimento, em duas fases, a primeira com 102 participantes e a segunda com 100, todos especialistas em enfermagem de reabilitação.

Resultados: embora com algumas alterações nos scores, o perfil de atitudes dos enfermeiros de reabilitação face à morte antes e depois do período crítico, manteve-se idêntico. Além do ténue aumento no score medo, a aceitação como aproximação foi a que registou maior aumento. Em relação ao evitamento, neutralidade e escape, os scores foram ligeiramente inferiores.

Conclusão: apesar dos sentimentos vivenciados pelos enfermeiros de reabilitação, as atitudes face à morte continuam a evidenciar preocupação em responder às necessidades das pessoas de quem cuidam, particularmente na fase final da vida.

Palavras-chave: atitude frente à morte; morte; enfermeiras especialistas; enfermagem em reabilitação; infeções por coronavírus; hospitais

\section{RESUMEN}

Objetivo: analizar las diferencias en el perfil de actitudes de las enfermeras de rehabilitación hacia la muerte antes y después del primer período crítico de la pandemia de COVID-19.

Método: estudio cuantitativo, comparativo, antes y después del período crítico. La recopilación de datos se realizó mediante un cuestionario autoadministrado, en dos fases, una primera con 102 participantes y una segunda con 100, todos especialistas en enfermería de rehabilitación.

Resultados: aunque con algunos cambios en los puntajes, el perfil de las actitudes de las enfermeras de rehabilitación hacia la muerte antes y después del período crítico, se mantuvo igual. Además del ligero aumento en el puntaje de miedo, la aceptación como aproximación fue la que registró el mayor aumento. En cuanto a la evitación, la neutralidad y el escape, las puntuaciones fueron ligeramente inferiores.

Conclusión: a pesar de los sentimientos experimentados por las enfermeras de rehabilitación, las actitudes hacia la muerte continúan mostrando preocupación al responder a las necesidades de las personas que cuidan, particularmente en la fase final de la vida.

Palabras clave: actitud frente a la muerte; muerte; enfermeras especialistas; enfermería en rehabilitación; infecciones por coronavirus; hospitales

\section{ABSTRACT}

Objective: to analyze the differences in the profile of attitudes of rehabilitation nurses towards death before and after the first critical period of the COVID-19 pandemic. 
Method: quantitative, comparative study, before and after the critical period. Data collection took place through a self-administered questionnaire, in two phases, a first with 102 participants and a second with 100, all specialists in rehabilitation nursing.

Results: although with some changes in the scores, the profile of attitudes of rehabilitation nurses towards death before and after the critical period, remained the same. In addition to the slight increase in the fear score, acceptance as an approximation was the one that registered the greatest increase. Regarding avoidance, neutrality and escape, the scores were slightly lower.

Conclusion: despite the feelings experienced by rehabilitation nurses, attitudes towards death continue to show concern in responding to the needs of the people they care for, particularly in the final phase of life.

Keywords: attitude to death; death; nurse specialists; rehabilitation nursing; coronavirus infections; hospitals

\section{INTRODUÇÃO}

A pandemia causada pelo Severe Acute Respiratory Syndrome Coronavirus 2 (SARS-CoV-2), mais conhecida por COVID-19, surgiu de forma inesperada e rodeada de indefinições sobre a sua etiopatogenia, bem como repleta de incertezas tanto no momento do diagnóstico, como no tratamento, o que implicou insegurança nos comportamentos a adotar nas diversas situações. Todavia, emergiram tomadas de decisão governamentais e institucionais para fazer face ao desconhecido, antecipando de certa forma, as necessidades e tentando controlar o que se previa dramático do ponto de vista social, económico e da saúde ${ }^{(1-2)}$.

Certo é que, num momento em que era urgente reinventar e reaprender perante um cenário desafiador $^{(3)}$, os profissionais de saúde tornaram-se imprescindíveis para fazer face às crescentes exigências de reorganização dos cuidados ${ }^{(1,4)}$. Neste puzzle diário, os enfermeiros especialistas em enfermagem de reabilitação continuaram a ser peças alicerçais na assistência em enfermagem ${ }^{(5)}$. Como especialistas, e com a visão alargada que lhes é permitida pelos conhecimentos que detêm e pela proximidade que habitualmente têm com as pessoas doentes e com as suas famílias, os enfermeiros de reabilitação tornaram-se mais uma vez, elos fundamentais numa fase em que a comunicação e a organização dos cuidados sofreram alterações inimagináveis.

Entre a criatividade e os recursos tecnológicos raramente utilizados na área da saúde, a confiança estabelecida entre o enfermeiro de reabilitação, a pessoa doente e a família alcançou níveis muito superiores ao usual. Por detrás de equipamentos que mal permitiam visualizar o profissional, estava uma voz associada a um nome que marcava a presença e a confiança declarada de que se iria fazer tudo o que era possível pela recuperação e bem-estar das pessoas em situação de doença.

O toque e a presença constantes, que tanto marcam a profissão de enfermagem, foram fortemente abalados. Tratam-se de circunstâncias marcadas por barreiras físicas intransponíveis como é o caso das luvas e a porta da enfermaria fechada, que impedem a proximidade em todos os momentos, mas sobretudo no acompanhamento nos últimos minutos de vida. E aqui sim, a pandemia trouxe um novo paradigma, tanto para o enfermeiro especialista em enfermagem de reabilitação como para qualquer profissional de saúde. Estes doentes que num determinado momento, aparentemente estão bem, facilmente desencadeiam descompensação respiratória grave e inesperada exigindo aos profissionais um estado de alerta permanente, para uma decisão de escalada terapêutica e/ou para uma decisão de conforto(6).

O desafio foi, sem dúvida, muito grande, pela adaptação que o enfermeiro especialista em enfermagem de reabilitação teve de fazer, perante novos objetivos traçados no âmbito do processo de cuidados. Neste contexto, a atuação do enfermeiro de reabilitação teve, algumas vezes, uma perspetiva paliativa, no sentido em que o importante seria aliviar sintomas físicos e/ou psicológicos. A sua presença constitui uma oportunidade de estar com a pessoa em situação de doença, de atender a todas as suas necessidades, estabelecendo prioridades para a sua resolução. Tratou-se de reinventar a cada momento, dentro das condicionantes exigidas, e de forma a proporcionar o que pode fazer toda a diferença, quer seja na manutenção/ recuperação das funções, quer no bem-estar emocional e espiritual, despertando o sentimento de compaixão tantas vezes esquecido ${ }^{(7)}$.

No contexto nacional, bem como no internacional, a pandemia por COVID-19, ficará marcada por um elevado número de mortes ${ }^{(8)}$. Atendendo à complexidade da situação clínica de vários doentes com COVID-19, um número significativo dessas mortes ocorre em instituições hospitalares, ou seja, na presença dos profissionais de saúde, nomeadamente enfermeiros, e particularmente, enfermeiros especialistas em enfermagem de reabilitação, que têm, com mais frequência do que o habitual, de lidar com a morte e o processo de morrer ${ }^{(9)}$.

A vivenciar uma experiência profissional e pessoal sem precedentes, a saúde física e mental dos profissionais de saúde tem sido motivo de forte preocupação, essencialmente pela repercussão que a exposição ao stresse pode vir a ter no bem-estar destes profissionais $^{(10)}$.

Além dessa dimensão, é amplamente conhecido que não há uma única forma de vivenciar o processo de morrer e que as atitudes dos profissionais de saúde face à morte influenciam os cuidados prestados, na medida em que são determinantes no âmbito do seu processo de tomada de decisão(11). Neste sentido, e atendendo ao momento vivenciado, será que as atitudes dos enfermeiros especialistas em enfermagem de 
reabilitação face à morte são diferentes em contexto de crise pandémica?

Perante o exposto, o objetivo deste estudo foi analisar as diferenças no perfil de atitudes dos enfermeiros especialistas em enfermagem de reabilitação face à morte antes e depois do primeiro período crítico da pandemia por COVID-19.

\section{MÉTODO}

Estudo quantitativo, comparativo, antes e depois do primeiro período crítico da pandemia por COVID-19, e realizado num Centro Hospitalar Universitário da região Norte de Portugal. A técnica de amostragem usada foi não probabilística de conveniência. Como critérios de inclusão definiram-se: enfermeiros com especialização em enfermagem de reabilitação e a trabalhar nos serviços dos Departamentos de Medicina, Cirurgia e Cuidados Intensivos. De um universo de 159 enfermeiros especialistas em enfermagem de reabilitação, a amostra ficou constituída no primeiro momento por 102 enfermeiros especialistas em enfermagem de reabilitação e no segundo momento por 100 enfermeiros com a mesma especialização.

Como instrumento de colheita de dados usou-se um questionário de autopreenchimento constituído numa primeira parte por um conjunto de 12 questões de caraterização sociodemográfica e numa segunda parte, pela escala de Avaliação do Perfil de Atitudes acerca da Morte (EAPAM). A EAPAM, já validada em Portugal ${ }^{(12)}$, é composta por trinta e duas questões fechadas onde perante cada uma das afirmações é possível responder numa escala tipo likert que varia de 1 (discordo totalmente) a 7 (concordo completamente). Neste estudo, a escala apresentou um Alfa de Cronbach 0,853, o que demostra uma boa consistência interna.

O primeiro momento de colheita de dados foi em fevereiro de 2018 e a segunda recolha de dados decorreu de 15 a 31 de maio de 2020. Em ambos os momentos, o questionário foi distribuído por um investigador, em todos os serviços de internamento de adultos, dos Departamentos de Medicina, Cirurgia e Cuidados Intensivos, sendo posteriormente, recolhidos em envelopes fechados. Importa referir que os enfermeiros foram esclarecidos acerca dos objetivos e informados de que a sua participação seria voluntária, não sendo prejudicados se não quisessem participar ou em caso de desistência.

Para análise dos dados foi utilizada a estatística descritiva e analítica. O estudo foi aprovado pela comissão de ética do Centro Hospitalar em estudo, com o número 102/2017, com a adenda de extensão do trabalho, aprovada em 29 de maio de 2020.

\section{RESULTADOS}

A amostra foi constituída por 202 enfermeiros especialistas em enfermagem de reabilitação, 102 no primeiro momento, e 100 no segundo. O perfil dos participantes caracterizou-se por 133 mulheres $(65,8 \%)$ e 69 homens $(34,2 \%)$, com idades compreendidas entre os 26 e 59 anos, cuja idade média foi de 38,95 anos, com um desvio padrão de 5,988. No que diz respeito ao perfil sociodemográfico dos participantes verificámos que as amostras do primeiro e do segundo momento de colheita de dados se mantêm com caraterísticas semelhantes, não ocorrendo diferenças significativas quando efetuado o cálculo do Qui-quadrado de Pearson. A maioria dos 202 participantes $(65,8 \%)$ eram casados ou viviam em união de facto, $28,2 \%$ solteiros e 5,9\% divorciados. Em relação aos enfermeiros que participaram na $1^{\mathrm{a}}$ e $2^{\mathrm{a}}$ fases, ocorreram algumas diferenças no estado civil: diminuiu a percentagem de solteiros de $34,2 \%$ para $22,0 \%$ e aumentou a percentagem de casados de $60,8 \%$ para $71,0 \%$. Dois casos passaram para o estado de divorciados. Estes enfermeiros que antes e após o primeiro período crítico da pandemia por COVID-19, trabalhavam nas áreas em estudo, durante a pandemia referem que exerceram funções nomeadamente na área médica $(41,5 \%)$, na área intensiva $(26,4 \%)$, na área cirúrgica $(22,6 \%)$, noutra área $(7,5 \%)$ e na área da Urgência $(1,9 \%)$.

$\mathrm{Na}$ segunda fase da colheita de dados, quando questionados sobre o facto de nos últimos meses terem trabalhado numa área de atendimento COVID-19, 53 participantes $(26,2 \%)$ responderam afirmativamente; os restantes $(73,8 \%)$ não trabalharam em serviços de atendimento COVID-19.

Dos 100 participantes da segunda fase, ou seja, depois do primeiro período crítico da pandemia por COVID-19, apenas $15,0 \%$ esteve ausente do hospital de março a abril, sendo que a maioria $(85,0 \%)$ manteve-se em funções.

Em relação às atitudes face à morte, considerando o total da amostra, verificámos que o medo teve uma variação de 12 a 49 pontos, ocorrendo a média nos 27,61, com um desvio padrão de 8,057. Quando analisada esta atitude no segundo momento, houve um ligeiro aumento, a média passou a ser de 28,01, com um desvio padrão de 7,837. O gráfico 1 mostra as variações das pontuações no antes e depois, evidenciando que algumas vezes as frequências são semelhantes, como ocorre na pontuação 28 , próxima do ponto médio.

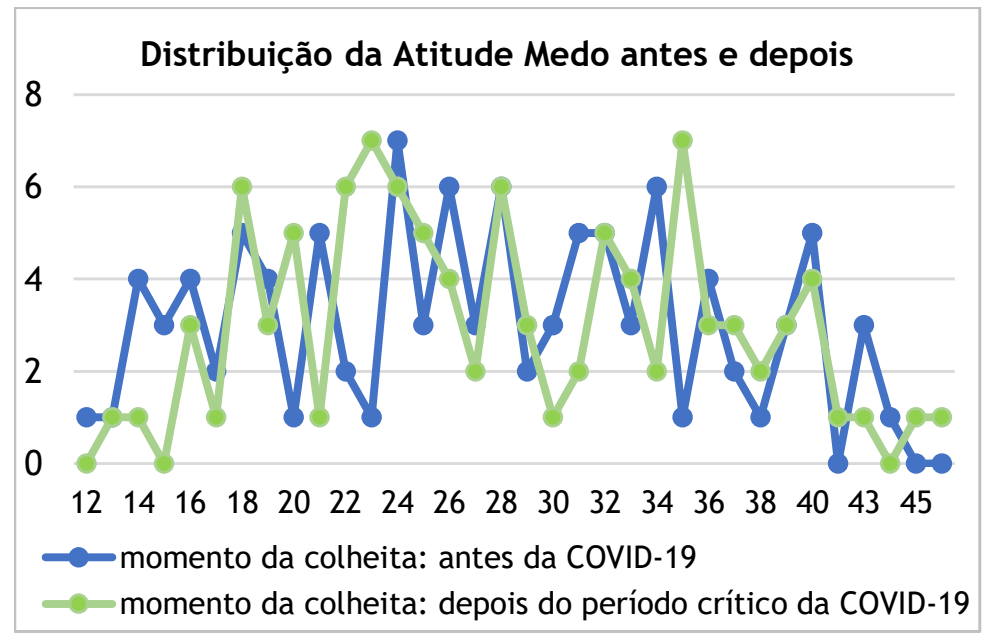

Gráfico 1 - Variação da atitude Medo face à morte, antes e depois do primeiro período crítico da pandemia por COVID-19.

Quando analisada a atitude de evitamento, verificámos que na amostra total a variação foi de 5 a 35 pontos, 
sendo a média de 17,98 , com um desvio padrão de 7,494. Quando comparados os dois momentos, antes da COVID-19 a média foi de 18,05, com um desvio padrão de 7,576 e após o primeiro período crítico da pandemia por COVID-19, a média passou para 17,90 , com um desvio padrão de 7,447. A distribuição verificada no gráfico 2 demonstra que a maior frequência ocorreu na pontuação 10.

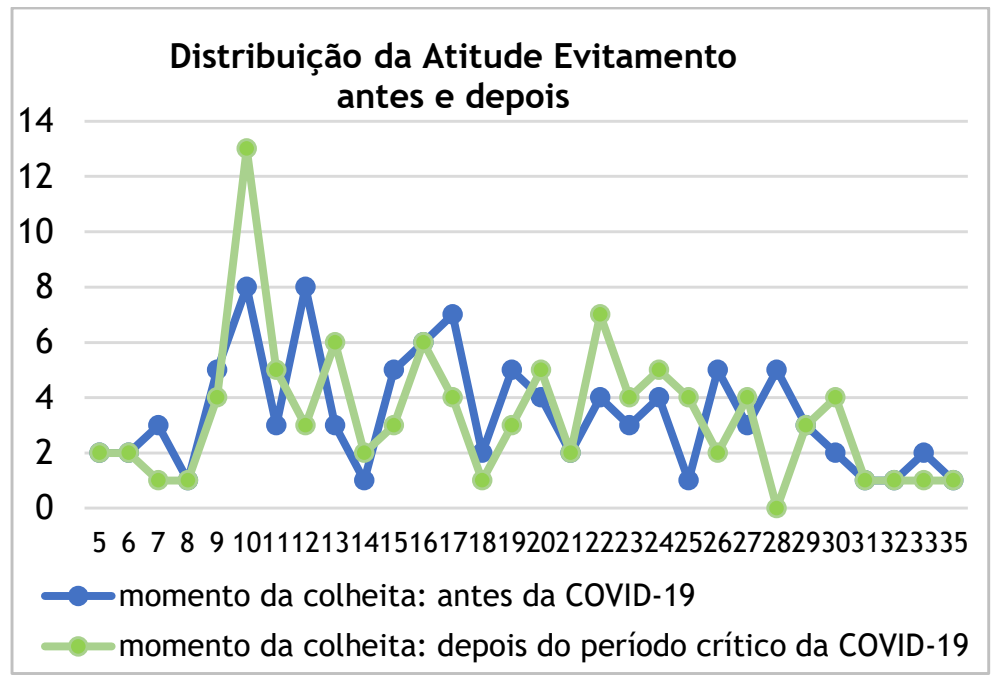

Gráfico 2 - Variação da atitude Evitamento face à morte, antes e depois do primeiro período crítico da pandemia por COVID-19.

Sobre a atitude aceitação como aproximação, que determina que as crenças religiosas nos aproximam da noção de que a morte pode trazer a paz e a harmonia, verificámos que a variação foi de 10 a 70 pontos, com uma média de 38,57 e um desvio padrão de 10,627, valor em torno da média mais elevado quando comparadas todas as componentes. $\mathrm{Na}$ análise dos dados dos dois momentos, verificámos que antes da COVID-19, a média foi de 38,00 com um desvio de 10,181 e depois do primeiro período crítico da pandemia por COVID-19, a média ficou nos 39,15, aumentando o desvio padrão para 11,086. A distribuição do gráfico 3 expressa um pico nos dois momentos na pontuação 40.

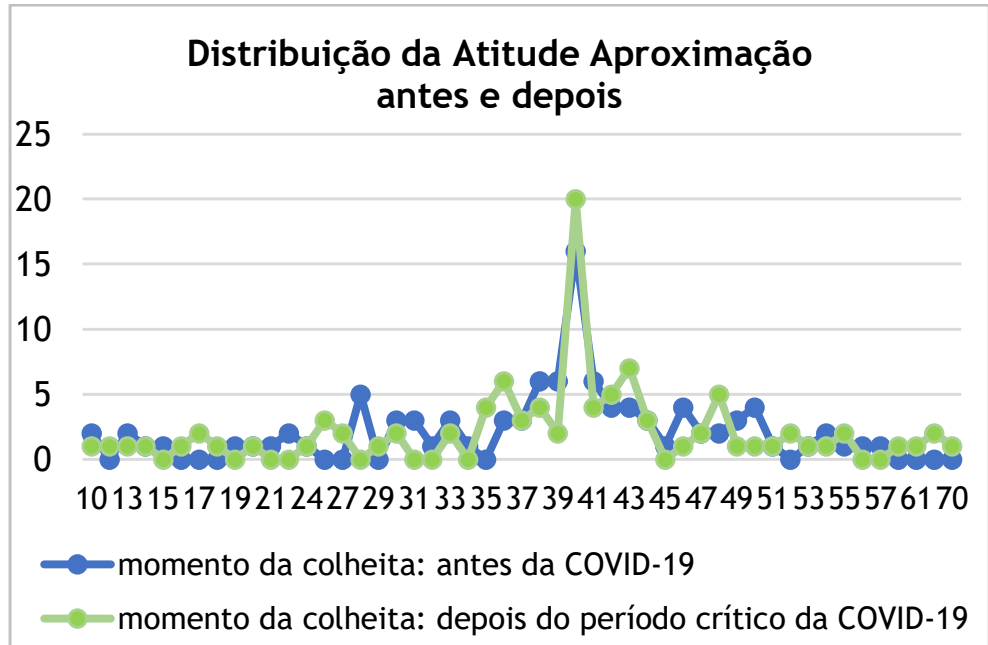

Gráfico 3 - Variação da atitude Aceitação como Aproximação, antes e depois do primeiro período crítico da pandemia por COVID-19.

Sobre a aceitação como escape, isto é, quando se vive em certas circunstâncias que acarretam dor e sofrimento para o indivíduo, sendo a morte uma alternativa para o término desse sofrimento, verificámos que a pontuação variou de 5 a 27 pontos, apresentando uma média de 15,31 e um desvio padrão de 5,680. Na análise dos dados dos dois momentos, verificámos que antes da COVID-19, a média era de 15,36 e o desvio padrão 5,723 e depois do primeiro período crítico da pandemia por COVID-19, mantiveram-se valores semelhantes, com uma média de 15,26 e o desvio padrão de 5,665. Quando analisado o gráfico 4 , verificámos nos dois momentos um pico na pontuação 20.

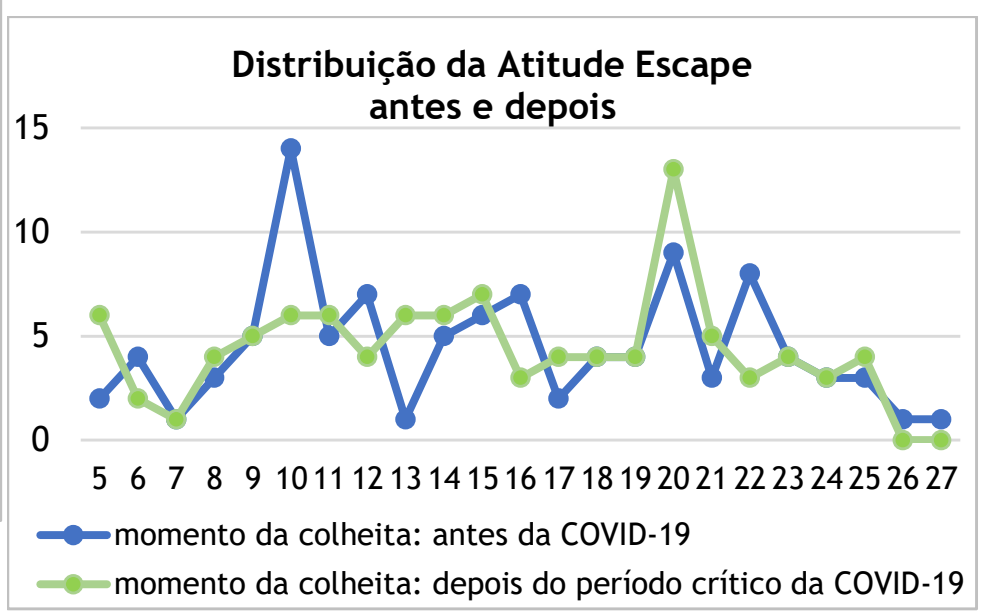

Gráfico 4 - Variação da atitude Aceitação como Escape, antes e depois do primeiro período crítico da pandemia por COVID-19.

Quando analisada a atitude aceitação neutral/ neutralidade perante a morte, que é perspetivada como parte integrante do ciclo de vida, verificámos uma variação de 18 a 35 pontos, com uma média nos 27,63 e um desvio padrão de 3,748. Comparando os dados antes e depois, verificámos muitas semelhanças: no momento antes, a média era de 27,74 e o desvio padrão de 3,694, e no momento depois, a média situava-se nos 27,53 e o desvio padrão nos 3,818. Na distribuição do gráfico 5 constatámos o pico mais elevado na pontuação 28, no período antes da COVID-19.

\section{Distribuição da Atitude Neutralidade antes e depois}

20

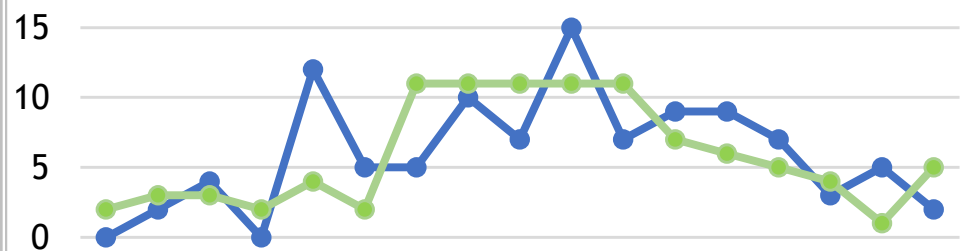

1820212223242526272829303132333435

-momento da colheita: antes da COVID-19

- momento da colheita: depois do período crítico da COVID-19

Gráfico 5 - Variação da atitude Aceitação Neutral/ Neutralidade, antes e depois do primeiro período crítico da pandemia por COVID19.

Por último, ao analisar a escala total verificámos uma variação de 73 a 187 pontos, sendo o valor médio de 127,10 , com um desvio padrão de 20,632. Acresce ainda 
que surgiram diferenças na média: antes da COVID-19 era de 126,37 e depois do primeiro período crítico da pandemia por COVID-19 foi de 127,85, existindo um aumento do desvio padrão de 19,605 para 21,714. A distribuição dos valores demonstra um pico na pontuação 134 , depois do período crítico da pandemia por COVID-19.

\section{Distribuição dos valores totais da escala antes e depois}

4

3

2

1

0

73808991939598102104106108110112114116118120122124126128130132134136138141143145147150152154156158160164170177

-momento da colheita: antes da COVID-19 - momento da colheita: depois do período crítico da COVID-19

Gráfico 6 - Variação dos valores totais da escala, antes e depois do primeiro período crítico da pandemia por COVID-19.

Para explorar as diferenças de distribuições dos valores por variável, recorremos ao teste não paramétrico $U$ de Mann-Whitney para as variáveis dicotómicas e ao Teste de Kruskal-Wallis para as restantes, considerando amostras independentes e um nível de significância de 0,05 . Na Tabela 1 estão explanados os resultados em relação às variáveis sexo, idade e estado civil.

Tabela 1 - Análise da significância dos componentes das atitudes face à morte e variáveis sociodemográficas

\begin{tabular}{|l|c|c|c|}
\hline \multicolumn{1}{|c|}{ EAPAM/ Dimensões } & Sexo & Idade & $\begin{array}{c}\text { Estado } \\
\text { Civil }\end{array}$ \\
\hline Valor Total da Escala & 0,687 & 0,194 & 0,533 \\
\hline Medo & 0,800 & 0,931 & 0,041 \\
\hline Evitamento & 0,968 & 0,828 & 0,959 \\
\hline Aceitação como Aproximação & 0,518 & 0,294 & 0,097 \\
\hline Aceitação como Escape & 0,634 & 0,021 & 0,434 \\
\hline Aceitação Neutral/ Neutralidade & 0,204 & 0,242 & 0,005 \\
\hline
\end{tabular}

Face às hipóteses nulas podemos afirmar que a distribuição foi a mesma entre o sexo e as várias dimensões. No que se refere à idade, verificámos que a distribuição é igual em várias dimensões, exceto na atitude aceitação como escape, em relação à qual existem diferenças de mediana por classes de idades, sendo os mais velhos os que têm um valor de mediana mais elevado (Gráfico 7).

Perante o estado civil dos participantes também constatámos diferença de distribuição para o medo e para a aceitação neutral/ neutralidade. A distribuição do medo nos casados ou a viver em união de facto tem um intervalo maior e uma mediana mais elevada (Gráfico 8).

No que concerne à aceitação neutral/ neutralidade, confirmou-se maior dispersão no grupo dos solteiros, contudo os divorciados foram o grupo com mediana mais elevada (Gráfico 9).

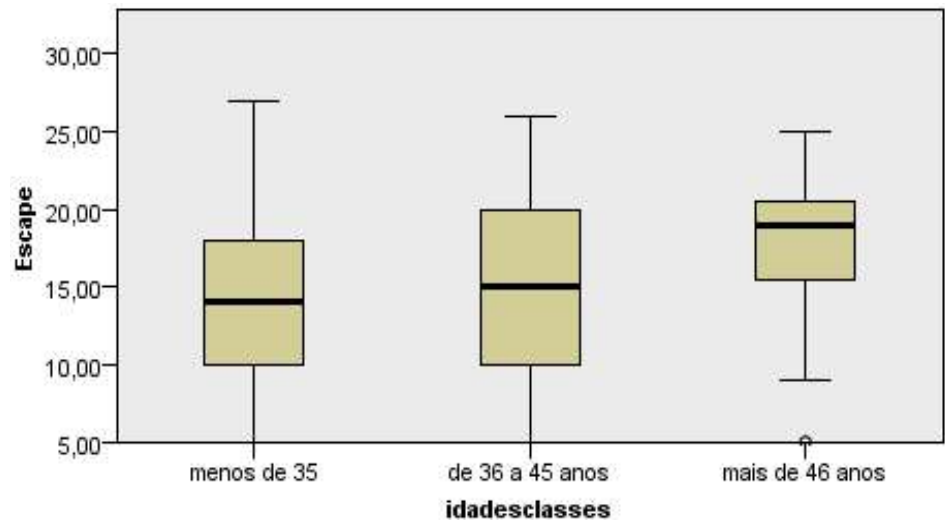

Gráfico 7 - Distribuição da atitude Aceitação como Escape por classes de idades.

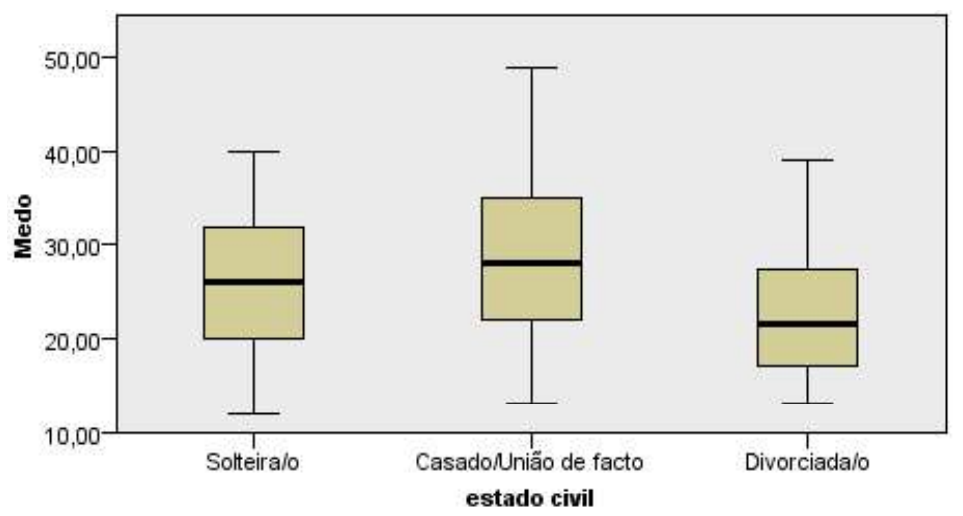

Gráfico 8 - Distribuição da atitude Medo por estado civil.

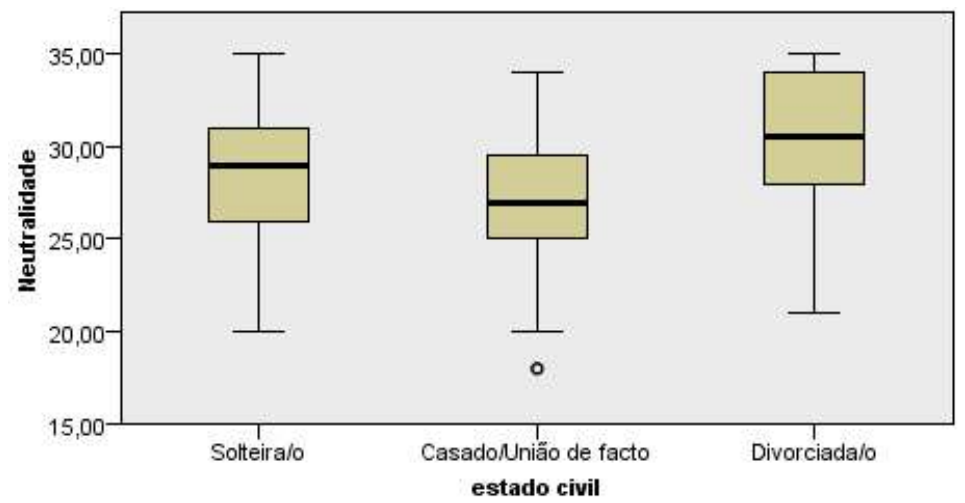

Gráfico 9 -Distribuição da atitude Aceitação Neutral/ Neutralidade por estado civil. 
Quando analisados os valores relativamente ao facto dos enfermeiros especialistas em enfermagem de reabilitação terem trabalhado ou não nos últimos meses numa área de atendimento COVID-19, verificámos não existir diferenças de distribuição. Por outro lado, a ausência durante os meses de março a abril revelou diferenças na atitude aceitação como aproximação (Tabela 2).

Tabela 2 - Análise da significância dos componentes das atitudes face à morte e variáveis profissionais

\begin{tabular}{|c|c|c|c|}
\hline $\begin{array}{c}\text { EAPAM/ } \\
\text { Dimensões }\end{array}$ & $\begin{array}{c}\text { Área de } \\
\text { atendimento } \\
\text { COVID-19 }\end{array}$ & $\begin{array}{c}\text { Outra } \\
\text { área onde } \\
\text { trabalhou }\end{array}$ & $\begin{array}{c}\text { Ausente do } \\
\text { hospital de } \\
\text { março a abril'20 }\end{array}$ \\
\hline $\begin{array}{c}\text { Valor Total } \\
\text { da Escala }\end{array}$ & 0,291 & 0,692 & 0,290 \\
\hline Medo & 0,964 & 0,452 & 0,877 \\
\hline Evitamento & 0,265 & 0,200 & 0,892 \\
\hline $\begin{array}{c}\text { Aceitação } \\
\text { como } \\
\text { Aproximação }\end{array}$ & 0,853 & 0,333 & 0,017 \\
\hline $\begin{array}{c}\text { Aceitação } \\
\text { como Escape }\end{array}$ & 0,062 & 0,448 & 0,805 \\
\hline $\begin{array}{c}\text { Aceitação } \\
\text { Neutral/ } \\
\text { Neutralidade }\end{array}$ & 0,671 & 0,099 & 0,713 \\
\hline
\end{tabular}

De facto, no que se refere à atitude aceitação como aproximação, verificámos uma diferença na distribuição dos valores entre as ausências do hospital nos meses de março e abril para os que responderam não e sim, com os pontos médios, respetivamente 53,4 e 34,07 (Gráfico 10).

não

$\operatorname{sim}$

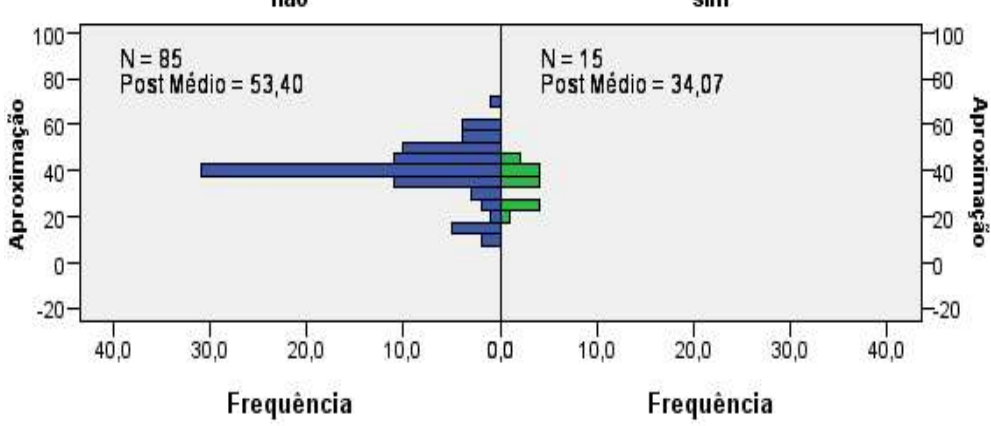

Gráfico 10 - Distribuição da atitude Aceitação como Aproximação e ausências do hospital nos meses de março a abril de 2020.

Por fim, explorámos a distribuição dos grupos antes e depois do primeiro período crítico da pandemia por COVID-19 para cada dimensão e para a escala total. Verificámos não existir diferenças de distribuição nos dois testes usados (Tabela 3).

Em síntese, constatámos que globalmente os enfermeiros especialistas em enfermagem de reabilitação perante a pandemia por COVID-19 mantiveram as mesmas atitudes face à morte.
Tabela 3 - Análise da significância dos componentes das atitudes face à morte, antes e depois do primeiro período crítico da pandemia por COVID-19.

\begin{tabular}{|c|c|c|}
\hline EAPAM/ Dimensões & $\begin{array}{c}\text { Teste de } \\
\text { Mediana de } \\
\text { amostras } \\
\text { independentes }\end{array}$ & $\begin{array}{c}\text { Teste U } \\
\text { de } \\
\text { Mann- } \\
\text { Whitney }\end{array}$ \\
\hline Valor Total da Escala & 0,948 & 0,651 \\
\hline Medo & 0,890 & 0,563 \\
\hline Evitamento & 0,994 & 0,895 \\
\hline Aceitação como Aproximação & 0,908 & 0,562 \\
\hline Aceitação como Escape & 0,994 & 0,948 \\
\hline Aceitação Neutral/ Neutralidade & 0,909 & 0,707 \\
\hline
\end{tabular}

\section{DISCUSSÃO}

O aparecimento de uma pandemia acarreta consigo consequências devastadoras, onde a morte e o processo de morrer fazem parte, em muitos casos inesperadamente, sem pré-aviso ${ }^{(13)}$, tal como tem acontecido na pandemia causada pelo SARS-CoV-2. A população foi surpreendida por um vírus de alto contágio que em poucos meses sobrelotou hospitais, refez e alterou formas de trabalho ${ }^{(1-2)}$. Os profissionais de saúde reinventaram-se e adaptaram-se a novas estratégias para a prestação de cuidados, e o mundo tem vindo a ajustar-se a uma nova realidade.

De modo a assegurar os cuidados necessários, os enfermeiros especialistas em enfermagem de reabilitação não foram exceção a essa reinvenção e adaptação durante a pandemia, até porque uma das suas competências específicas se reporta ao cuidar de pessoas com necessidades especiais, ao longo do ciclo vital e em todos os contextos da prática de cuidados ${ }^{(14)}$.

A prestação de cuidados durante a pandemia, face aos dados epidemiológicos conhecidos ${ }^{(8)}$, fez com que os profissionais de saúde, inclusive os enfermeiros especialistas em enfermagem de reabilitação, lidassem diariamente com um crescente número de óbitos. A morte e processo de morrer fez e continua a fazer parte das vivências destes profissionais, gerando atitudes perante este acontecimento que poderiam, ou não, ser diferentes, face às alterações que diariamente surgem no contexto dos cuidados, na sequência da COVID-19, o que explica a relevância deste estudo.

Face às diferentes variáveis, os dados sociodemográficos das amostras antes e depois do primeiro período crítico da pandemia por COVID-19 não evidenciaram alterações significativas, o que corrobora a fiabilidade das mesmas.

No que diz respeito aos contextos de trabalho, os enfermeiros especialistas em enfermagem de reabilitação mantiveram-se a prestar cuidados nas suas habituais áreas de trabalho, sendo que $53,0 \%$ esteve a prestar cuidados em áreas de atendimento a doentes com COVID-19. Isto explica-se pelo facto de face ao aumento do número de casos diários e à necessidade de prestação de cuidados diferenciados, diversos serviços tiveram de se adaptar a uma nova realidade, quer no 
âmbito da prestação de cuidados, quer no perfil de doentes admitidos ${ }^{(1,4)}$.

De um modo geral, de acordo com os resultados apresentados, os enfermeiros especialistas em enfermagem de reabilitação mantiveram as suas atitudes face à morte durante a pandemia. No entanto, em relação à atitude medo, houve um ligeiro aumento. A morte e o processo de morrer durante a pandemia por COVID-19 gerou pensamentos e sentimentos muito relacionados com a ansiedade perante um vírus, até então desconhecido. Além disso, a forma como a COVID-19 causa lesões nos processos fisiológicos das pessoas e a necessidade de cuidados muito diferenciados, por exemplo, com recurso a ventilação invasiva e não invasiva de forma quase constante, aproximava o processo de morrer ${ }^{(1)}$, podendo constituir uma justificação para o aumento do score no medo destes profissionais face à morte. Acresce ainda que nos enfermeiros especialistas em enfermagem de reabilitação cujo estado civil era casado, o medo foi superior. 0 facto de os profissionais de saúde estarem em contacto diário com a pandemia e regressarem a casa onde estava a sua família, agravava o medo de contágio(10) . A mesma alteração não se verificou com os participantes solteiros ou divorciados, talvez pelo facto de mais facilmente conseguirem manter algum afastamento da família.

A atitude evitamento, embora não apresentasse uma alteração significativa, teve pontos inferiores. Evitar falar ou pensar sobre a morte, é, algo que se torna impossível face aos casos diários vivenciados e frequentemente veiculados na comunicação social.

O aumento da atitude aceitação como aproximação, associada às crenças religiosas, que sendo especialmente resgatadas em tempo de crise pandémica, podem ter contribuído para o controlo das emoções e para a diminuição da ansiedade dos participantes na prestação de cuidados ${ }^{(15)}$. Importa destacar que no caso dos enfermeiros que estiveram ausentes durante os meses de março e abril, época alta do primeiro pico da pandemia em Portugal, existiram diferenças significativas. 0 facto de não vivenciarem a prestação de cuidados nessa fase, não precipitou nesses enfermeiros um aumento na atitude aceitação como aproximação.

As crenças religiosas adquiriram assim ênfase na atitude dos participantes perante a morte, pelo aumento do score na dimensão aceitação como aproximação. 0 surgimento desta pandemia revelou-se uma situação inesperada. A não existência de um fármaco ou de um tratamento especificamente dirigido à doença gerou e gera uma procura de solução na fé, numa superioridade $\operatorname{divina}^{(16)}$.

Em relação às restantes atitudes face à morte, embora as diferenças não fossem significativas, quer a aceitação neutral/ neutralidade, quer a aceitação como escape, diminuíram simbolicamente. Embora a morte seja parte integrante do ciclo vital, se não surgisse esta pandemia muitas pessoas não morreriam neste momento. Além disso, em diversos casos, apesar da presença de várias comorbilidades, as pessoas doentes não estavam em sofrimento para que a morte fosse considerada uma alternativa, o que pode justificar uma diminuição no score da atitude aceitação como escape. Contudo, importa destacar que na classe etária mais elevada, os enfermeiros especialistas em enfermagem de reabilitação apresentaram maior incidência desta atitude. A experiência profissional, associada às vivências pessoais e ao conhecimento histórico de outras epidemias e pandemias elevam a aceitação como o fim de um sofrimento a que ninguém está imune numa situação de emergência ${ }^{(16)}$.

É sabido que os profissionais de saúde atualmente em exercício de funções não tinham passado pela experiência de trabalhar num contexto desta natureza, e apesar dos múltiplos sentimentos de incerteza e insegurança, que podem influenciar a adaptação ao momento critico e, aumentar a fragilidade e instabilidade psicossocial mantiveram o rigor e o envolvimento crucial à garantia da qualidade dos cuidados prestados. 0 desafio instalou-se nas diferentes áreas de trabalho e os enfermeiros especialistas em enfermagem de reabilitação aceitaram-no. Considerando a incerteza um perigo, mas também uma oportunidade, estes enfermeiros entenderam que a situação com que se deparavam exigia adequadas atitudes, que nos momentos finais da vida, devem voltar-se para maior conforto físico e psicoemocional da pessoa doente ${ }^{(17,18)}$. Neste sentido, a prestação de cuidados foi adaptada, mas sempre com foco no bemestar da pessoa em situação de doença. De facto, a reabilitação pode muitas vezes não seguir o caminho de reabilitar para a vida, mas proporcionar um estado de bem-estar no processo de morrer ${ }^{(19)}$.

A não existência de alterações significativas nas atitudes dos enfermeiros especialistas em enfermagem de reabilitação face à morte antes e depois do primeiro período crítico da pandemia por COVID-19, assim como a ainda escassa informação sobre a temática, dificultaram a discussão dos resultados obtidos. No entanto, a abordagem desta problemática traz contributos para a análise e introspeção do cuidado prestado e desenvolvido num contexto atípico de cuidados, de forma a que no futuro se desenvolvam estratégias que favoreçam e melhorem o cuidado prestado pelos enfermeiros especialistas perante a morte e processo de morrer, reduzindo o impacto negativo que este acontecimento possa ter na vida de quem a vivencia.

\section{CONCLUSÃO}

O facto das atitudes dos enfermeiros especialistas em enfermagem de reabilitação face à morte antes e depois do primeiro período crítico da pandemia por COVID-19 terem evidenciado praticamente o mesmo perfil, merece uma reflexão. Embora estes profissionais estivessem a ultrapassar um momento sem precedentes, também desencadeador neles próprios de sentimentos de angústia, ansiedade e preocupação, as atitudes face à morte continuaram a denotar o seu envolvimento na resposta às necessidades evidenciadas pelas pessoas de quem cuidam, particularmente na fase final da vida. A par do ténue aumento no score do medo, perfeitamente compreensível, a aceitação como 
aproximação foi a atitude que registou o maior aumento, o que mais uma vez, vem relevar o papel da religião perante condições que se preveem difíceis de resolver apenas com a intervenção humana.

Esta crise pandémica impôs uma necessidade de reajuste nas relações pessoais, profissionais e sociais, que se espera ter desencadeado uma aprendizagem para o futuro, uma vez que o conhecimento adquirido por esta experiência, dificilmente se obteria de outra forma.

No âmbito das instituições de saúde, a resposta à pandemia exigiu um efetivo trabalho em equipa, no entanto, perante a gravidade da situação clínica de vários doentes com COVID-19, a intervenção dos enfermeiros especialistas em enfermagem de reabilitação foi fundamental. Apesar do esforço multidisciplinar, em inúmeras situações, perante a impossibilidade de resolver os compromissos nas funções corporais, a morte e o processo de morrer exigiram uma atuação diferenciada dos enfermeiros e, particularmente dos especialistas em enfermagem de reabilitação. Atendendo às particularidades do seu exercício profissional, os enfermeiros e em especial os enfermeiros especialistas em enfermagem de reabilitação, são os elementos da equipa de saúde que passam mais tempo e em maior proximidade com as pessoas em situação de doença, sendo que em contexto de crise pandémica, as suas atitudes face à morte podem ser determinantes.

\section{REFERÊNCIAS BIBLIOGRÁFICAS}

1. Almeida JA. Medicina Interna do Centro Hospitalar Universitário S. João na Pandemia COVID-19. Rev Soc Port Med Interna. [Internet]. 2020. [cited 2020 Jun 02];1-6 Available from: https://www.spmi.pt/revista/covid19/covid19_202005_36.pdf]

2. Direção Geral da Saúde. Plano Nacional de Preparação e Resposta à Doença por novo coronavírus (COVID-19) [Internet]. Lisboa: Direção-Geral da Saúde; 2020 [cited 2020 Jun 02]. Available from: https://www.dgs.pt/documentos-e-publicacoes/plano-nacionalde-preparacao-e-resposta-para-a-doenca-por-novo-coronaviruscovid-19-pdf.aspx

3. Miranda FMA, Santana L de L, Pizzolato AC, Saquis LMM. Working conditions and the impact on the health of the nursing profissionals in the context of Covid-19. Cogitare enferm. [Internet]. 2020 [cited 2020 May 16];25: e72702. DOI: $10.5380 /$ ce.v25i0.72702.

4. Santos M, Fernandes MA. Medicina Interna na Linha da Frente: Exemplo de um Hospital Não Central. Rev Soc Port Med Interna. [Internet]. 2020 [cited 2020 Jun 02]; Available from: https://www.spmi.pt/revista/covid19/covid19_maio2020_20_24 .pdf

5. Portugal. Regulamento $n .^{\circ} 140 / 2019$, de 6 de fevereiro de 2019. Dispõe o Regulamento das Competências Comuns do Enfermeiro Especialista. Diário da República. 2019 fev; 2. ${ }^{a}$ série. p 4744$4750 . \quad$ Available from: https://www.ordemenfermeiros.pt/media/10778/0474404750.p df

6. Lima CMAO. Information about the new coronavirus disease (COVID-19). Radiol Bras. [Internet]. 2020 [cited 2020 Jun 02];53(2):V-VI. DOI: 10.1590/0100-3984.2020.53.2e1

7. Rocha C; Oliveira H. Cuidados Paliativos na Pandemia COVID-19. Rev Soc Port Med Interna. [Internet]. 2020 [cited 2020 Jun 02]. Available https://www.spmi.pt/revista/covid19/covid19_202005 32.pdf

8. World Health Organization. Portal da WHO. [Internet]. Genebra: WHO; 2020 [cited 2020 Apr 04]. Available from: https://covid19. who.int/
9. Cardoso MF, Martins MM, Ribeiro O. Nursing care documentation during the dying process - How do the rehabilitation nurses differ?. Rev Port Enferm Reabil [Internet]. 2019 [cited 2020 Apr 04];2(2):33-40. Available from: https://www.aper.pt/ficheiros/revista/RPERv2n2.pdf

10. Carqueja E. Quantos mais psicólogos necessita o SNS para que a população tenha de facto acesso a cuidados de saúde integrais?. Revista Oficial da Ordem dos Psicólogos Portugueses. [Internet]. 2020; [cited 2020 Jun 02];28-20. Available from: https://www.ordemdospsicologos.pt/ficheiros/documentos/psis 21_especial_covid.pdf

11. Machado RS, Oriá MOB, Fernandes MA, Gouveia MTO, Silva GRF. Translation and cultural adaptation of Death Attitude Profile Revised (DAP-R) for use in Brasil. Texto Contexto Enferm. [Internet]. 2019 [cited 2020 Apr 09];28:e20180238. DOI: 10.1590/1980-265x-tce-2018-0238

12. Loureiro LMJ. Translation and adaptation of the Revised Death Attitude Profile (DAP-R). Rev Enf Ref. [Internet]. 2010 [cited 2020 Apr 10];III(1):101-108. DOI: 10.1590/1980-265x-tce-2018-0238

13. Lima RS, Júnior JAC. The process of death and dying in nurses vision. ReOnFacema. [Internet]. 2015 [cited 2020 Jun 02]; 1(1): 25-30. Available from: http://www.facema.edu.br/ojs/index.php/ReOnFacema/article /view/13/8

14. Coelho A, Teixeira PM. A morte e o lito durante a pandemia. Jornal Observador [Internet]. 2020 [cited 2020 Jun 02]. Available from: https://observador.pt/opiniao/a-morte-e-o-luto-durantea-pandemia/

15. Portugal. Regulamento $n .^{\circ} 392 / 2019$, de 3 de maio de 2019. Dispõe o Regulamento das competências específicas do enfermeiro especialista em Enfermagem de Reabilitação. Diário da República. 2019 mai; $2 .^{a}$ série. p 13565-13568. Available from: https://dre.pt/web/guest/pesquisa//search/122216893/details/normal?l=1

16. Barros CCS, Rocha EL, Silva AF, Rodrigues PMS, Soares JO, Silva AV, Lima VLA. Enfrentamento da enfermagem diante do processo de morte e morrer: revisão integrativa da literatura. Rev Enferm Atual In Derme. [Internet]. 2019 [cited 2020 Jun 02]; 89(27):88$27 \quad$ Available from: https://revistaenfermagematual.com.br/index.php/revista/arti cle/view/408

17. Fernandes MFP, Komessu JH. Nurses' challenges in view of the pain and suffering of families of terminal patients. Rev Esc Enferm USP. [Internet]. 2013 [cited 2020 Jun 02]; 47(1):250-7. Available from: https://doi.org/10.1590/S008062342013000100032.

18. Ferreira JMG, Nascimento JL, Sá FC. Profissionais de saúde: um ponto de vista sobre a morte e a distanásia. Rev Bras Educ Med. [Internet]. 2018 [cited 2020 Jun 02];42(3):87-96; DOI: 10.1590/1981-52712015v42n3rb20170134. 